\title{
Corporate risk management a measure to enhance increase in profitability
}

\begin{abstract}
Risk management is about making the most opportunity, making the right corporate decision and about achieving objective once those decisions are made. This is achieved through transferring risks, controlling risks, and living with the risk. This qualitative research and employed descriptive analysis. This research paper anticipated when control and standard are in possession, corporate risk management; finance and operation risk will be effectively managed or mitigated.
\end{abstract}

Keywords: corporate, risk, flu action, mitigation, violate
Volume 2 Issue 5 - 2018

\author{
Emmanuel Teitey Ph.D \\ Eminent Consultancy \& African Research Center, Ghana
}

Correspondence: Emmanuel Teitey, Eminent Consultancy\& African Research Center Accra, Ghana, Tel +233 0548704485/0277430485, Email eminet1972@hotmail.com

Received: March 13, 2018 | Published: September 25, 2018

\section{Introduction}

\section{Corporate risk management a measure to enhance increase in profitability}

Risk management failures at Major Corporation have captured the headline for many years, primarily in the financial sector, moreover, in other sectors as well, and have not always been the results of inadequacies in financial risk-taking. Environmental disasters such as Bhopal and Seveso came to mind, as well as accounting fraud such as Enron and WorldCom, to name just a few. In most cases, these failures were (at least) facilitated by corporate governance failures, where boards did not fully appreciate the risk that the companies were taking (if they were not engaging in reckless risk-taking themselves, and/or deficient risk management systems.

Corporate risk has been addressed in the Committee's thematic Reviews following the financial crisis and the collapse of some organisation. Remarkably in the review on board practice, where the Committee examined incentives influencing corporate risk-taking, notably with regard to compensations practices by Organization for Economic Cooperation and Development (OECD). ${ }^{1}$ The issue has also been dealt with by the OECD's Asian and Latin American Corporate Governance Discussions. The Financial Stability Board (FSB), in its recently issued Thematic Review on Risk Governance, called on the OECD to review its principles for governance, taking into consideration the sound risk governance practices list in the FSB report. ${ }^{1}$

Risk management is about making the most opportunity (making the right corporate decision) and about achieving objective once those decisions are made. This is achieved through transferring risks, controlling risks, and living with the risk. Risk management is not just about insurance, not least because $80 \%$ of risks faced by the organisation are not insurable. Certainly, risk transfer is part of risk management, but so is risk retention and control. ${ }^{2}$

\section{Problem of the study}

One of the major deficiencies regarding corporate risk management involves noncompliance, about internal control and procedure, regulation and constitution of the organizations. Organization talk about enterprise risk management (ERM) as an essential and worthy concept and then struggle to implement it. ERM means different things to different corporations, but essentially, it can be managed much as any other high-level priority. ERM strategy involves identifying, analyzing, monitoring and directing internal and external risk factors and leveraging controls to significantly lower risk. Such enterprisewide risks include, but are not limited to, liability, compliance, financial, operational, strategic and reputation-related.

\section{Theoretical framework}

Many innovation projects finish far from their initial estimates and are surrounded by uncertainties. Goffin ${ }^{3}$ indicated that the development of new products, services and processes is inherently uncertain, and dealing with risk and uncertainty is fundamental to the management of innovation. In their work of managing uncertainty in projects, Meyer ${ }^{4}$ noted that risk management is directed to the identification and control of variations and predictable uncertainties. However, for innovation project or projects embedded in dynamic environments, wherein large uncertainties are concentrated, one should go beyond the traditional methods of risk management and adopt fewer techniques focused on planning and more directed to flexibility and learning.

\section{Methodology}

Data on corporate risk management was collected from Secondary sources like Articles, Journals, empirical literatures, Textbooks and Internet sources (peer-review data) for analysis on corporate risk. Qualitative methodology was applied for this research paper. Descriptive research design and analysis on corporate risk were employed to investigate the corporate risk management system. For the purpose of analysis, a secondary data was used to analyse the various literature on corporate risk. The researcher obtained both primary and secondary data from the various case studies for the analysis of the corporate risk. The primary data was in the form of interviews with concern officials for some organizations in Ghana. Secondary data was in the form of documents obtained from the internet (peer-review data), literatures reviewed and other articles for the analysis of the corporate risk management systems. 


\section{Results and discussion}

The empirical data analysed from the primary and secondary sources has shown that efficient and effective management of corporate risk and mitigation is good a measure of enhancing increase in profitability of an organisation, and this was possible due to results from the study enumerated as below:

Company reputation: An organisation reputation is one factor that promotes the organisation product, increase their market share and increase in the organizations profitability position. Public perception of the company, questions over ethical nature of company business or actions, controversies which may tarnish company image. This is called reputation/brand risk, in other to manage these risks or mitigate, the organisation must be serious with its ethical standard or the organizational culture.

Capital markets and economic condition: This type of risk occurs when the capital market and the entire economy is unstable. There are series of crisis such as currency fluctuation and devaluation, debt and equity violate, macro and regional economy inflation, and unemployment affects the monetary and fiscal policies of the country. This type of risk is referring as credit and interest rate risk. Further, to manage these risks, government must implement policies that would stabilize the economy. In the absent of that, the corporate organisation also need to be conscious about the type of economic variable affect system so as apply the right mitigation measures.

Corporate finance and operation: Revenue forecasts and other estimates and assumption must be done using the right standard, provisions and rate. Failure to do so must involve in financial and operational risk for the organisation, and revenue, estimates and assumption will be under or overstated. Financial performance may not be showing the clear indication. Short and long-term investment must apply the right mix (diversification). The exact safety measure must also be provided. When above controls and standard are introduced, finance and operation risk will be effectively managed or mitigated.

\section{Conclusion and practical recommendations}

The end of this research has been to generally fit the aims and objectives of this study. Recommendation for the future is however made to further improve upon the findings of this research. Based on the findings of the research, it is concluded and recommended that: A corporate risk management or mitigation is a measure that enhances corporate growth and profitability. The other factors such human capital and corporate growth strategies for corporate risk management and mitigation of organisation or a firm is next step for future studies.

\section{Acknowledgements}

None.

\section{Conflict of interest}

The author declares that there is no conflict of interest.

\section{References}

1. OECD. Thematic Review on Risk Governance report. Organization for Economic Cooperation and Development. 2011. 111 p.

2. Solace C. Corporate Risk Management Strategy. UK; 2016. 24 p.

3. Goffin K, Mitchell R. Innovation management. UK: Palgrave Macmillan; 2005. 440 p.

4. Meyer A, Loch CH, Pich MT. From variation to chaos. MIT Sloan Management Review. 2002;43(2):60-67. 